This is the peer reviewed version of the following article: Hill, M. et al_ 2019. Environmental factors are primary determinants of different facets of pond macroinvertebrate alpha and beta diversity in a humanmodified landscape. Biological Conservation 237: 348-357

which has been published in final form at https://doi.org/10.1016/i.biocon.2019.07.015

\title{
Environmental factors are primary determinants of different facets of pond macroinvertebrate alpha and beta diversity in a human-modified landscape
}

Running title: Pond biodiversity in a human-modified landscape

\begin{abstract}
Understanding the spatial patterns and environmental drivers of freshwater diversity and community structure is a key challenge in biogeography and conservation biology. However, previous studies have focussed primarily on taxonomic diversity and have largely ignored the phylogenetic and functional facets resulting in an incomplete understanding of the community assembly. Here, we examine_the influence of local environmental, hydrological proximity effects, land-use type and spatial structuring on taxonomic, functional and phylogenetic (using taxonomic relatedness as a proxy) alpha and beta diversity (including the turnover and nestedness-resultant components) of pond macroinvertebrate communities. Ninety-five ponds across urban and non-urban land-uses in Leicestershire, UK were examined. Functional and phylogenetic alpha diversity were negatively correlated with species richness. At the alpha scale, functional diversity and taxonomic richness were primarily determined by local environmental factors while phylogenetic alpha diversity was driven by spatial factors. Compositional variation (beta diversity) of the different facets and components of functional and phylogenetic diversity were largely determined by local environmental variables. Pond surface area, dry phase length and macrophyte cover were consistently important predictors of the different facets and components of alpha and beta diversity. Our results suggest that pond management activities aimed at improving biodiversity should focus on improving and/or restoring local environmental conditions. Quantifying alpha and beta diversity of the different biodiversity facets facilitates a more accurate assessment of patterns in diversity and community structure. Integrating taxonomic, phylogenetic and functional diversity into conservation strategies will increase their efficiency and effectiveness, and maximise biodiversity protection in human-modified landscapes.
\end{abstract}


Key Words: connectivity, functional traits, environmental filtering, macroinvertebrates, pond network, taxonomic distinctness

\section{Highlights}

- Functional and taxonomic alpha diversity were determined by local environmental factors

- Functional and phylogenetic beta diversity were determined by local environmental factors.

- Functional and phylogenetic beta diversity were determined by local environmental factors.

- Pond management activities should focus on improving local environmental conditions

- Taxonomic, functional and phylogenetic diversity should be integrated into conservation strategies.

\section{Introduction}

Understanding the spatial patterns and environmental drivers of diversity and community assembly are central to the fields of community ecology, biogeography and conservation biology (Richardson Whittaker, 2010; Socolar et al., 2016; Soininen, 2016). Examining spatial biodiversity patterns has typically been based on taxonomic richness (Ricklefs, 2004; Hill et al., 2018). However, focussing primarily on the taxonomic facet fails to acknowledge that biotic assemblages are composed of taxa with different evolutionary histories and functional roles within ecosystems (Cardoso et al., 2014), which may not provide a complete or comprehensive understanding of the community assembly (Heino and Tolonen, 2017a). Current diversity measures largely ignore the fact that a change in species numbers or environmental conditions can have a significant effect on evolutionary legacy or ecosystem functioning, as taxonomic diversity treats species as evolutionarily equivalent and functionally similar entities (Arnan et al., 2017). Recently, research has begun to recognise that multiple aspects of biodiversity, such as phylogenetic and functional diversity, need to be specifically considered and that in doing so it may provide complementary information to increase our understanding of the mechanisms shaping patterns of biodiversity (Meynard et al., 2011; Cisneros et al., 2015; Heino and Tolonen, 2017b;). Phylogenetic diversity reflects the evolutionary history of an ecological community (Webb et al., 2002) and as a result, communities with identical taxonomic diversity may demonstrate significant phylogenetic diversity depending on the evolutionary history of the organisms at specific sites (Cardoso et al., 2014). Functional diversity refers to the aspects of biodiversity that influence ecosystem functioning and incorporates the diversity of phenotypic (morphological and physiological) and ecological traits within a biotic community (Petchey and Gaston, 2006). Both mismatches and congruencies between functional, phylogenetic and taxonomic diversity have been recorded among biotic communities (Devictor et al., 2010). For example, sites with high taxonomic richness may be characterized by low functional diversity, as different taxa 
among sites may possess similar functional roles (Villeger et al., 2012); while other studies have shown taxonomic richness to be correlated to phylogenetic and functional diversity (Heino and Tolonen 2017a). Incorporating functional and phylogenetic approaches into biodiversity research may provide a greater understanding of ecosystem functioning-environment associations (Dray et al., 2014), variation in community productivity (Cadotte et al., 2009), the resilience of ecosystem functioning (Thornhill et al., 2018), and the evolutionary constraints on patterns in community composition (Webb et al., 2002).

Biodiversity can be divided into alpha, gamma, and beta diversity (Whittaker, 1960. Gamma diversity represents the total species diversity in the landscape (Whittaker, 1960). Alpha diversity represents the taxonomic richness within an individual (local) site; while beta diversity refers to the compositional variation in communities among sites within a pre-determined area (Whittaker, 1960). Total beta diversity can be further partitioned into nestedness and turnover components (Baselga, 2010). Species turnover refers to the replacement of species from one site to another; while the nestedness component of beta diversity refers to taxa in species poor sites representing a subset of species within high diversity sites (Baselga et al., 2012; Legendre, 2014). In this study, we focussed on alpha and beta diversity, as this enables an understanding of the processes that drive phylogenetic, functional and taxonomic diversity, and compositional variation at the gamma scale (Heino and Tolonen, 2017a, b). At a local (alpha) scale, phylogenetic, functional, and taxonomic diversities have been shown to vary slightly and to be significantly influenced by different environmental variables in lentic macroinvertebrate metacommunities (Heino and Tolonen 2017a). Recent pond and lake studies have also found that phylogenetic, functional and taxonomic beta diversity (and their turnover and nestedness components) are typically explained by local environmental factors at the landscape-scale (Gianuca et al., 2017; Heino and Tolonen 2017b). However, at larger scales, spatial variables, such as those associated with dispersal limitation, may explain more of the variation in macroinvertebrate assemblages compared to environmental gradients (Cai et al., 2018). Despite this, to our knowledge no studies have examined the influence of environmental and spatial variables on the turnover and nestedness components of macroinvertebrate phylogenetic and functional beta diversity within pond habitats (defined here as lentic waterbodies $<2$ ha in area). This approach may further increase our understanding of community assembly processes in small lentic ecosystems (Myers et al. 2013; Gianuca et al., 2018).

Biodiversity conservation almost exclusively focusses on taxonomic diversity (EC, 1992; Strayer Dudgeon, 2010), despite global environmental changes influencing ecosystem functioning (often independently from changes in taxonomic diversity) and phylogenetic diversity through a loss of evolutionary history and opportunities for future diversification (Devictor et al., 2010). Further, protected areas delineated primarily on taxonomic diversity may be incongruent with sites of high functional or phylogenetic diversity, suggesting that focussing solely on taxonomic diversity for conservation decisions may be based on an incomplete representation of biodiversity (Devictor et al., 2010; Strecker et al., 2011; Arnan et al., 2017). Functional and phylogenetic diversity can be better 
predictors of ecosystem productivity, vulnerability and stability than taxonomic diversity, and may therefore provide critical information, and contribute to the identification of sites that provide more effective, resilient and comprehensive biodiversity conservation (Strecker et al., 2011). Conservation of pond habitats has been demonstrated to be most effective at the landscape-scale, reflecting the high beta diversity (species turnover) and environmental heterogeneity (Williams et al., 2003; Hill et al., 2017). Examining beta diversity (and the nested and turnover components) of all three facets of pond diversity could provide additional information required to increase the effectiveness of landscapescale pond conservation. However, the contribution of functional and phylogenetic alpha and beta diversity to biodiversity conservation remains poorly quantified across freshwater habitats.

In this study, we examined the relative influence of local environmental and spatial variables on taxonomic, functional and phylogenetic facets of alpha and beta diversity (and their turnover and nestedness-resultant components). We hypothesised: (1) that local environmental factors would overcome the effects of spatial and landscape-type factors for taxonomic, functional and phylogenetic (taxonomic relatedness) alpha diversity, and (2) that local environmental factors would be the most important factor driving phylogenetic (taxonomic relatedness) and functional total beta diversity, and the nestedness-resultant and turnover components of beta diversity, based on the results of previous studies (Heino and Tolonen 2017a; Hill et al., 2017; Gianuca et al 2018; Rocha et al., 2018). Finally, we discuss the implications of the biodiversity-environment and biodiversity-space relationships for ecological conservation and management in human-modified landscapes.

\section{Materials and Methods}

\subsection{Study area}

A total of 95 ponds were studied across a c. $280 \mathrm{~km} 2$ area in Leicestershire, UK (for a detailed outline of the study area, see Hill et al., 2017). Ponds selected for study were located in: (1) urban landscapes (Loughborough: $\sim 35 \mathrm{~km} 2$, approx. population of 60,000) including urban parks, school grounds, roadsides, high density commercial developments (such as sustainable urban drainage ponds in city centres and industrial areas) and domestic gardens, and (2) non-urban landscapes including floodplain meadows (located in nature reserves protected for nature conservation), woodland (oak or mixed woodland - oak, silver birch, alder and European ash) and agricultural land (dominated by one or two crops such as rapeseed or wheat). Considerable variability in environmental characteristics was recorded among the ponds selected for study (Table 1).

\subsection{Environmental data collection and spatial variables}

A total of 10 local environmental variables measured within each pond comprised: surface water area (m2), mean water depth (cm), percentage of pond covered by submerged, emergent and/or floating macrophytes, dissolved oxygen (percentage saturation), $\mathrm{pH}$, percentage of pond margin shaded, dry phase length (duration that the pond was dry over the 12-month period - 27 ponds dried for between 3 
and 7 months) and conductivity (_ S cm -1). A total of four spatial variables were included in this study; pond isolation, pond connectivity, PCNM eigenvectors and landscape type. Pond isolation (the number of aquatic habitats within $500 \mathrm{~m}$ of the sampled pond) and pond connectivity (the number of other aquatic habitats hydrologically connected through surface links to the focal pond site), defined as 'hydrological proximity effects' (Hill et al., 2017) were measured at each site. The hydrological proximity effects were recorded using aerial imagery (Google Earth, 2017), ordnance survey maps and field observations. While every attempt was taken to record all aquatic habitat within $500 \mathrm{~m}$ of each study site, we acknowledge that a small number of ephemeral and garden ponds may have been overlooked in this study, as they are often not recorded on national maps (e.g., OS MasterMap) and difficult to identify from satellite imagery. Principal coordinates of neighbour matrices (PCNM; a total of 14 eigenvectors were derived in this study) were created using the PCNM package in R (Borcard and Legendre 2002; Legendre et al., 2012). PCNM creates a series of spatial variables to quantify the overall spatial structure in biological communities. The truncation threshold was calculated as the longest distance in the minimum spanning tree (Legendre et al., 2012), and only the eigenvectors that model positive spatial autocorrelation were used in the statistical analyses. Spatial eigenvectors have been suggested to better capture spatial patterns in ecological communities than latitude and longitude as the eigenvectors can represent the spatial structuring of study sites at a range of scales (Borcard and Legendre 2002, Dray et al. 2012). Each pond's location within the urban or non-urban landscape was recorded.

\subsection{Macroinvertebrate field surveys}

Aquatic macroinvertebrate samples were taken during the spring (March), summer (June) and autumn (September) seasons in 2012, following the National Pond Survey sampling methods (Biggs et al., 1998). Full details of field sampling are outlined in Hill et al., (2015) and summarised here. Sampling time allocated at each pond site was proportional to its surface area; for every $10 \mathrm{~m} 2$ surface area 30 seconds of sampling time was allocated up to $50 \mathrm{~m} 2$, with ponds greater than $50 \mathrm{~m} 2$ sampled for 3 minutes. The sweep technique was used to collect samples from the available mesohabitats (e.g., open water, emergent macrophytes, submerged macrophytes and floating macrophytes) in each pond. Sampling time at each pond was divided equally among the mesohabitats present. However, if one mesohabitat dominated, sampling time was proportionally divided to reflect this (Biggs et al., 1998). Mesohabitat samples from each pond were pooled for the final analyses. A visual examination of larger substrates that could not be sampled with a pond net (e.g., wood debris and rocks) was undertaken at each pond for a maximum of 60 seconds. The majority of macroinvertebrate taxa were identified to species level, however Physidae, Planariidae and Diptera larvae were resolved to family level and Oligochaeta, Collembola and Hydrachnidiae were recorded as such. Seasonal macroinvertebrate data from individual ponds were pooled (see Hill et al., (2017) Appendix part 1 for preliminary analyses of individual season macroinvertebrate data) and the mean values of environmental parameters were derived. 


\subsection{Macroinvertebrate trait and phylogenetic data}

Macroinvertebrate functional traits were derived from a trait database developed by Tachet et al., (2010) and applies to fauna residing within European freshwater habitats (Usseligo-Polatera et al., 2000)Functional traits are reported here by their 'grouping feature' (represents a functional trait category) and 'traits' (represents the modalities residing within individual grouping features) (see Schmera et al., 2015; White et al., 2017 for terminology). A total of 11 grouping features were used in this study representing the phenotypic properties of fauna: body size, life cycle duration, potential number of cycles per year, aquatic stages, reproduction, dispersal, resistance forms, respiration, locomotion-substrate relation, food and feeding habit. A total of 63 traits from the 11 grouping features were used in this study (see Table S1 for species traits for each grouping feature). These biological grouping features and traits were selected as they provide the fundamental biological characteristics of freshwater macroinvertebrates (Tachet et al., 2010; Merrit and Cummins, 1996), as opposed to their ecological preferences. Trait information within the database is typically available at species- or genus-level and only taxa resolved to an equal or lower taxonomic resolution within this study were included within the functional analyses. As such, a total of 11 taxa out of 228 were excluded as they were deemed to possess high functional variability (or were identified at a too coarse level); Ceratopogonidae, Chaoboridae, Chironomidae, Chrysomelidae, Dixidae, Empididae, Simuliidae, Diptera Other, Hydrachnidiae, Planariidae, Collembola, Hydrophilidae larvae, Dytiscidae larvae, Scirtidae larvae and Sphaeriidae. In addition, trait information was lacking for some taxa: Dicranota sp., Cercyon marinus, Callicorixa wollastoni, Succinea putris, and Zonitidae. Where trait information was only available for macroinvertebrates at the genus level, species were aggregated to the genus level.

As the true phylogenetic tree was unavailable for the macroinvertebrate taxa recorded in this study, taxonomic distance based on the path lengths in the taxonomic trees was used as a proxy for the true phylogenetic tree. The derived taxonomic tree used equal branch lengths and seven taxonomic levels (species, genus, family, suborder, order and phylum), which were based on numerous aquatic macroinvertebrate identification keys (Macan 1977; Elliot and Mann 1979; Hynes, 1984; Fres, 1985; Elliot et al., 1988; Friday, 1988a; Savage, 1989; Smith, 1989; Gledhill et al., 1993; Edington and Hildrew 1995; Wallace et al., 2003; Cham, 2009 and; Foster and Friday 2011).

\subsection{Statistical analyses}

\subsubsection{Alpha diversity}

All statistical analyses were performed in the R environment (R Core Team, 2016). The taxa abundance macroinvertebrate dataset was converted into a presence-absence dataset prior to alpha and beta diversity statistical analyses (see Fig. S1, S2 and S3 for the taxonomic, functional and phylogenetic alpha and beta diversity statistical procedures).

Using the derived taxonomic tree outlined above (as a surrogate for a phylogenetic tree), taxonomic 
distances between species were calculated using the function taxa2dist in the vegan package (Oksanen et al., 2017). To determine trait distances between species, the Gower dissimilarity was calculated using the original trait data, using the function gowdis from the FD package (Laliberte et al., 2014), Mean pairwise distance (MPD) indices were used to calculate observed taxonomic relatedness (proxy for phylogenetic diversity) among sites (using the taxonomic distances between species), and functional alpha diversity (using the Gower dissimilarity of the trait dataset and species presence abundance data). MPD for taxonomic relatedness and functional data was calculated using the function ses.mpd from the picante package (Kembel et al., 2016). MPD was chosen as the alpha diversity index in this study as the ses.mpd function can use any species-by-species distance matrix (e.g., Gower dissimilarity) as input in addition to a site-by-species matrix. Taxonomic relatedness has been used in other studies examining phylogenetic diversity and demonstrated to be a suitable proxy for true phylogeny when it is unavailable (Ruhi et al., 2013; Heino and Tolonen 2017a; Cai et al. 2018; Heino and Tolonen 2018). Taxonomic alpha diversity was calculated as the taxonomic richness (number of taxa) in each sampled site.

To examine the environmental variables significantly explaining the variation in taxonomic, functional and phylogenetic alpha diversity, partial linear regression was undertaken. Initially, separate partial linear regression analyses (for taxonomic, functional and phylogenetic alpha diversity) employing a forward selection process (using the function ordiR2step in the vegan package) was undertaken to identify the significant local environmental variables, hydrological proximity effects, and spatial eigenvectors influencing taxonomic, phylogenetic and functional alpha diversity. Three stopping rules were employed when applying this forward selection method: (1) once the adjusted R2 begins to decrease, (2) once the permutational significance level was exceeded $(=0.05)$ and (3) once the full model adjusted R2 was exceeded (Hill et al., 2017; Oksanen et al., 2017). Environmental parameters were $\log 10$ transformed to downweight extreme values consistently across all abiotic parameters (Legendre and Birks 2012). Variance partitioning analysis (Borcard et al., 1992), based on partial linear regression, was undertaken to identify the pure and shared contribution of 4 sets of predictors; (1) local environmental conditions, (2) hydrological proximity effects, (3) landscape type and (4) spatial structuring (PCNM eigenvectors) on phylogenetic and functional alpha diversity (observed MPD). Variance partitioning analysis was performed using the varpart function in the vegan package. Statistical significance of the four sets of predictors and the full model were calculated using the anova function. The adjusted R2 fractions are presented in this study as they provide unbiased estimations of explained variation which corrects for the number of explanatory variables (Peres-Neto et al., 2006).

Pearson correlation (r) was calculated (using the function cor.test in the stats package) to examine the correlation between the taxonomic, functional and phylogenetic alpha diversity among pond sites. Moran's I correlograms were constructed to examine the degree of spatial autocorrelation of phylogenetic alpha diversity, functional alpha diversity of the MPD for phylogenetic and functional 
communities, using the function correlog in the pgirmess package (Giraudoux, 2017).

\subsubsection{Beta diversity}

We examined variation in macroinvertebrate phylogenetic and functional total beta diversity, and the turnover and nestedness-resultant components. RDA was chosen as the constrained ordination method to analyse the variation in phylogenetic and functional beta diversity in relation to local and spatial explanatory variables (Legendre and Legendre 2012). Taxonomic beta diversity was not analysed here as it has previously been examined (Hill et al. 2017). For phylogenetic beta diversity analyses, taxonomic distance (as a proxy for true phylogeny) between macroinvertebrate taxa was calculated using the taxa2dist function (Heino and Tolonen 2017b). A taxonomic tree was constructed by building a clustering tree using the function hclust (using the 'complete' agglomeration method), and converting the clustering tree into a taxonomic tree using as.phylo function in the ape package (Paradis et al., 2017). Pair-wise distance matrices based on the Sørensen dissimilarity (using a site-by species matrix and the taxonomic tree), accounting for the phylogenetic nestedness-resultant and turnover components of beta diversity, and total beta diversity, were calculated using the phylo.beta.pair function in the betapart package (Baselga et al., 2017). Principal coordinate analyses (PCoA, with Lingoes correction accounting for negative eigenvalues) was undertaken on the three taxonomic distance matrices (turnover, nestedness-resultant and total beta diversity) using the function pcoa in the ape package (as performed by Hill et al., 2017)_to derive 'taxonomic vectors' describing species taxonomic relatedness. The principal coordinates (eigenvectors) for the three taxonomic dissimilarity matrices were used as response variables in separate variance partitioning analyses. For functional beta diversity analyses, the dimensionality of the original trait data was reduced, and trait distances between species were calculated using the Gower distance (Gower, 1971) using the function gowdis. PCoA was undertaken on the trait Gower dissimilarity matrix using the function pcoa. Only the first two PCoA vectors were used in calculating convex hull volumes shaping any two communities in functional space, as further dimensions caused overly long computational times. Three functional pair-wise distance matrices (using a site-by-species matrix and quantitative traits data, in this case two PCoA trait vectors) accounting for the functional turnover and nestedness resultant components of beta diversity, and total beta diversity were calculated using the functional.beta.pair function in the betapart package (based on Sørensen dissimilarity; Heino and Tolonen 2017b). On each of the functional dissimilarity matrices (nestedness-resultant, turnover and total beta diversity), PCoA analyses were undertaken using the function pcoa. The principal coordinates (eigenvectors) for the three functional dissimilarity matrices were used as response variables in separate variance partitioning analyses.

Prior to variance partitioning analysis, environmental variables were transformed $(\log 10)$. RDA analyses using a forward selection process (using the function ordiR2step) were performed on functional and phylogenetic total beta diversity, and the functional and phylogenetic nestedness resultant and turnover matrices (as represented by the corresponding principal coordinates, see 
above), to identify the significant local environmental and spatial parameters (hydrological proximity effects, PCNM eigenvectors). To examine the individual and shared contribution of local environmental variables, hydrological proximity effects, land-use type and spatial structuring (PCNM eigenvectors) on the functional and phylogenetic total beta diversity, turnover and nestedness resultant dissimilarity matrices (based on the PCoA eigenvectors), variance partitioning analysis were undertaken as above. Separate variance partitioning analysis was undertaken on: (1) total phylogenetic beta diversity, (2) total functional beta diversity, (3) the functional nestedness-resultant component, (4) the phylogenetic nestedness-resultant component, (5) phylogenetic turnover, and (6) functional turnover. Significance of the full model and the contributions of the predictor groups (local environmental variable, land-use type, hydrological proximity effects and PCNM eigenvectors) was undertaken for each of the variance partitioning analyses using the anova function.

\section{Results}

In total, 228 macroinvertebrate taxa were recorded from 68 families and 21 orders from the studied pond sites. In terms of taxonomic richness, communities were dominated by insects, particularly Coleoptera (75 taxa), Hemiptera (32 taxa), Trichoptera (35 taxa), Odonata (19 taxa) and Diptera (14 taxa). Preliminary analyses indicated that dissimilarity (based on Sørensen dissimilarity) in functional and phylogenetic communities were significantly correlated (Mantel test: $r=0.87, p<0.001$ ). Taxonomic alpha diversity was significantly negatively correlated with functional (Pearson correlation: $r=-0.64, p<0.001$; Fig.1a) and phylogenetic alpha diversity (Pearson correlation: $r=-$ $0.39, \mathrm{p}<0.001$; Fig. 1b).

\subsection{Alpha diversity}

One hydrological proximity effect (connectivity) and three local environmental variables (percentage coverage of submerged macrophytes, conductivity, percentage dissolved oxygen) were identified to significantly influence functional alpha diversity. No PCNM spatial filters significantly influenced functional alpha diversity and were subsequently removed from the variance partitioning analysis (Fig. 2a). A total of $37.6 \%$ of variation in functional alpha diversity was explained by local and spatial parameters, based on the adjusted R2. Local environmental variables $(22.5 \%)$ was the only predictor group that significantly influenced functional alpha diversity and explained more of the statistical variation than hydrological proximity effects $(0 \%)$, and landscape type $(1.1 \%)$

Two PCNM spatial eigenvectors and one hydrological proximity effect (connectivity) were significant influences on phylogenetic alpha diversity. No local environmental variables significantly influenced phylogenetic alpha diversity and were excluded from the analyses. In total, 19.4\% of variation in phylogenetic alpha diversity was explained by the variance partitioning model (Fig. 2b). PCNM Spatial filters $(5.5 \%)$ was the only predictor group that significantly influence phylogenetic alpha diversity and accounted for more of the statistical variation than landscape type (1.4\%) and 
hydrological proximity effects (0.8\%; Fig. 2b).

When taxonomic alpha diversity (richness) was examined, six local environmental variables (pond surface area, dry phase length, percentage coverage of submerged macrophytes and floating macrophytes, conductivity, and percentage of the pond margin shaded), two hydrological proximity effects (connectivity and pond isolation) and one PCNM spatial filter influenced taxonomic alpha diversity. A total of $74.4 \%$ of variation in taxonomic alpha diversity was explained by the local and spatial variables (Fig. 2c). Local environmental parameters alone significantly explained taxonomic alpha diversity more effectively $(46 \%)$ than the hydrological proximity effects $(0.3 \%)$ and the PCNM spatial filters (5.6\%; Fig. 2c).

\subsection{Beta diversity}

Two significant PCNM spatial eigenvectors, two hydrological proximity effects (connectivity and pond isolation) and nine local environmental variables (pond surface area, dry phase length, dissolved oxygen concentration, percentage coverage of submerged macrophytes, emergent macrophytes and floating macrophytes, $\mathrm{pH}$, conductivity, and percentage of the pond margin shaded) were identified to influence total phylogenetic beta diversity A total of $32.6 \%$ of the variation in total phylogenetic beta diversity was accounted for by local and spatial variables. Local environmental variables alone explained phylogenetic beta diversity more effectively (19.5\%) than the PCNM spatial eigenvectors $(0.9 \%)$ and hydrological proximity effects (1.4\%; Fig. 3a).

When the total functional beta diversity was examined, landscape type, one PCNM spatial eigenvector and five local environmental variables (pond surface area, dry phase length, dissolved oxygen concentration, percentage coverage of submerged macrophytes, and percentage of the pond margin shaded) were significant in influencing functional beta diversity and used in the variance partitioning analysis. A total of $31.5 \%$ of the variation in total functional beta diversity was explained by local and spatial variables. Local environmental variables accounted for a greater proportion of the variance in functional beta diversity $(20.2 \%)$ than the landscape type $(2.3 \%)$ or spatial eigenvectors (1.9\%: Fig. $3 b)$.

Three significant spatial eigenvectors, one hydrological proximity effect (connectivity) and nine local environmental variables (pond surface area, dry phase length, pond depth, percentage coverage of submerged macrophytes, emergent macrophytes and floating macrophytes, $\mathrm{pH}$, conductivity, and percentage of the pond margin shaded) influenced pond phylogenetic turnover. A total of $18.7 \%$ of the variation in phylogenetic turnover could be explained by the local and spatial variables (Fig. 3c). Local environmental variables $(9.9 \%)$ and hydrological proximity effects $(0.7 \%)$ were the only predictor groups recorded to significantly influence phylogenetic turnover among ponds (Fig. 3c).

A total of three local environmental variables (pond surface area, pond depth and the percentage 
coverage of submerged macrophytes) were identified to significantly influence the variance in functional turnover. No PCNM spatial eigenvectors or hydrological proximity effects influenced the variability in functional turnover and were excluded from the variance partitioning analysis. A total of $10.9 \%$ of the variation in functional turnover was explained by local environmental variables and landscape type (Fig. 3d). Local environmental variables (7.7\%) and landscape type (1.1\%) both significantly influenced spatial patterns in functional turnover (Fig. 3d).

Spatial patterns of phylogenetic nestedness were significantly influenced by five local environmental variables (pond surface area, dry phase length, conductivity, percentage of the pond margin shaded and the percentage coverage of submerged macrophytes), and one hydrological proximity effect (pond isolation). No PCNM spatial filters significantly influenced spatial patterns of phylogenetic nestedness and were excluded from the variance partitioning analysis (Fig. 3e). A total of $31.4 \%$ of the variation in phylogenetic nestedness could be explained by the local and spatial variables examined. Local environmental variables explained more of the variation in phylogenetic nestedness (22\%) than hydrological proximity effects: (1.6\%) and landscape type (1\%; Fig. 3e).

A total of five local environmental variables (pond surface area, dry phase length, dissolved oxygen concentration, percentage coverage of submerged macrophytes, and percentage of the pond margin shaded) one hydrological proximity effect (connectivity) and one PCNM spatial eigenvector influenced spatial patterns of functional nestedness. A total of $35.5 \%$ of the variation in functional nestedness was explained by the local and spatial variables (Fig. 3f). Local environmental variables $(23.3 \%)$ explained more of the variation in spatial patterns of functional nestedness than landscape type $(2.3 \%)$, hydrological proximity effects $(0.7 \%)$, or the spatial eigenvectors $(0.7 \%)$.

\section{Discussion}

The results of this research have highlighted several ecologically important and interesting patterns that advance fundamental understanding on the phylogenetic, functional and taxonomic diversity patterns of lentic macroinvertebrate metacommunities. Taxonomic richness was most strongly explained by environmental variables, including pond surface area, dry phase length, macrophyte cover, conductivity and shading, which corresponds to the findings from multiple previous studies of small lentic waterbodies (including Oertli et al., 2002; Hassall et al., 2011; Heino, 2013; Heino et al., 2017c). Many of these variables are directly or indirectly related to 'area effects' (MacArthur Wilson, 1967), 'disturbance effects' (Vanshoenwinkel et al., 2013), and 'environmental heterogeneity effects' (Stein et al., 2014) on biodiversity, with increasing surface area, short dry periods and high macrophyte cover providing more habitat space (and structural complexity) for pond macroinvertebrates spatially and temporally. Taxonomic richness was also affected by hydrological proximity effects and spatial variables, but their unique effects were low. Similarly, functional alpha diversity was primarily driven by local environmental factors, and was minimally affected by spatial factors. Given the importance of dissolved oxygen and macrophyte cover in determining functional 
alpha diversity, this suggests that functional alpha diversity is locally determined by variables affecting macroinvertebrate traits responsible for respiration or traits that reflect adaptations to living in macrophyte beds (see Tachet et al., 2010). In contrast, phylogenetic alpha diversity was not significantly affected by local environmental factors but was most strongly correlated with spatial variables and secondarily with landscape type. This suggests that phylogenetic alpha diversity shows spatially-structured variation at the landscape-scale similar to that observed in previous studies conducted across broad spatial scales (Strecker et al., 2011; Cai et al., 2018). However, in our landscape-scale study, such spatial variation may be difficult to interpret as a signal of evolutionarily distinct lineages living in different parts of the study area, but rather as a sign that some spatially structured local environmental variables that influence phylogenetic alpha diversity were not accounted for in this study.

Patterns in total beta diversity were not as strong as those for alpha diversity, which is typical of studies centred on community structure. In this study the percentage of variation explained by local and regional variables was $<35 \%$, but this figure has been frequently reported to be much lower in other comparable studies on freshwater ecosystems (Heino et al., 2015; Hill et al., 2017). However, previous studies examining community assembly in freshwaters have almost exclusively focussed on taxonomic community structure (e.g., Vanschoenwinkel et al., 2007; Viana et al., 2016), whereas we utilised information on phylogenetic and functional features of pond macroinvertebrate communities. Rarely have these two facets been tested concurrently to examine community structural variation, so reference points are difficult to find in the literature. Gianuca et al. (2018) found that all three facets and components of biodiversity of pond zooplankton communities varied along an urbanization gradient, with land use close to a pond and local environmental variables being responsible for generating variation in functional traits and phylogenetic relatedness. Rocha et al. (2018) reported that of the spatial, climatic, catchment and local environmental variables they examined, only local environmental and spatial variables were important in determining variation in taxonomically-, functionally- and phylogenetically-defined stream macroinvertebrate communities, broadly corresponding to the findings of this study. We found that total functional and phylogenetic beta diversities were mostly affected by local environmental variables, suggesting that trait selection and taxonomic relatedness (used in our study as a surrogate for phylogenetic biodiversity) were determined at the local pond scale. This finding is plausible, given the relatively small geographical scale of this research (c. $280 \mathrm{~km} 2$ ) and the fact that at small spatial-scales, these facets should be predominantly shaped by environmental controls (Heino and Tolonen 2017b).

Variation in the turnover and nestedness-resultant components of taxonomic, functional and phylogenetic beta diversity were primarily determined by local environmental variables. Given that very few studies that have focussed on the turnover and nestedness components of beta diversity in freshwater ecosystems, broad comparisons are not possible. However, Gianuca et al. (2017) reported that local environmental factors, in terms of nutrient enrichment, negatively affected local taxonomic 
zooplankton diversity. This produced a pattern of beta diversity derived from nestedness in unconnected and environmentally heterogeneous landscapes. Increasing dispersal resulted in a weak pattern of nestedness, with the replacement component of beta diversity increasing in importance. Our findings did not provide as clear indications as Gianuca et al.'s (2017) study regarding the separation of the effects of dispersal and local environmental factors on the turnover and nestedness components of beta diversity. However, we found that the nestedness-resultant components of both functional and phylogenetic beta diversity were better explained by the predictor variables compared to the turnover components. For both components, pond surface area, dry phase length and macrophyte cover remained the most important predictors of beta diversity. This finding suggests that these are 'master' variables governing variation in pond macroinvertebrate communities, corroborating the findings of numerous previous studies (Rundle et al., 2002; Biggs et al., 2005; Hassall et al., 2011; Florencio et al., 2014; Hill et al., 2015; Heino and Tolonen, 2017b; Hill et al., 2017).

\subsection{Implications for biodiversity conservation}

Our study has direct implications for the conservation of pond biodiversity in human-modified landscapes characterised by multiple land-use types. First, it would be advisable for management activities to focus on improving or restoring local environmental conditions to support locally diverse pond faunas at a landscape-scale through increased environmental heterogeneity. For example, major foci should be pond surface area, depth, macrophyte cover and variation in hydroperiod length (Biggs et al., 2005; Hassall et al., 2011; Florencio et al., 2014; Thornhill et al., 2018). This is important because taxonomic and functional alpha diversity were primarily determined by local environmental conditions. In particular, increasing pond surface area and the coverage of submerged macrophytes will promote functional and taxonomic alpha diversity. However, given that no single site can support all species in a regional pool, promoting environmental heterogeneity among ponds should result in high levels of taxonomic, functional and phylogenetic beta diversity (Sayer et al., 2012). In addition, spatial effects were highlighted to be important for phylogenetic alpha diversity, but not for functional or taxonomic diversity. This low amount of variation in community data explained may be because measuring between-site connectivity (and consequent dispersal) is particularly difficult (Heino et al., 2017d). Consequently, more accurate measurements of the spatial structure of pond networks, may highlight a stronger influence of spatial structuring on biodiversity. Hence, increasing knowledge of connectivity effects on pond biodiversity (Oertli et al., 2008; Ribeiro et al., 2011) should also be a priority for conservation at a landscape-scale.

Recently, Cai et al., (2018) analysed broad-scale congruence among species richness, functional diversity and phylogenetic diversity using an approach similar to that reported here. They proposed that, as conservation planning is typically limited by available resources, defining priorities that simultaneously protect all biodiversity facets would be a desirable goal. Findings from some studies highlight that different facets of alpha diversity may be strongly correlated across broad spatial scales (e.g. Heino et al., 2008; Strecker et al., 2011), which suggests that protecting all facets and 
components of biodiversity simultaneously could be achieved by focussing on the protection of species richness. However, contradictory results have also emerged in studies at both national (Cai et al., 2018) and regional scales (Heino et al., 2005), where different facets of alpha diversity were weakly correlated. Our results demonstrate that for pond macroinvertebrates both functional and phylogenetic alpha diversity were negatively correlated with species richness. This pattern may be driven by the properties of each facet of diversity whereby increases in species richness and functional diversity may only generate a small change in phylogenetic diversity (Cai et al. 2018). Furthermore, the negative association between taxonomic richness and functional diversity may be driven by high redundancy or high niche differentiation within the regional metacommunity (Siqueira et al. 2012; Wellnitz and Poff 2001). Implementing conservation strategies using a single facet of diversity (typically taxonomic richness) as a cure-for-all should be avoided (Devictor et al., 2010). Instead, our results suggested that the three distinct facets of alpha diversity cannot be used as good surrogates of one another, but rather that conservation of pond macroinvertebrate biodiversity in human-modified landscapes requires a multi-faceted approach incorporating different biodiversity facets. However, focussing conservation efforts exclusively on different facets of alpha diversity is also unlikely to be effective. Quantifying the beta diversity (total, turnover and nestedness-resultant components) of the different biodiversity facets facilitates a more accurate and complete assessment of compositional variation, and the identification of the most suitable locations for biodiversity conservation that incorporate all diversity facets (Socolar et al., 2016). Indeed, high beta diversity is typically associated with high gamma diversity and, therefore, focussing conservation actions on maintaining both beta and gamma diversity should be a priority (Bush et al., 2016). This can likely be achieved by guaranteeing environmental heterogeneity among ponds at the landscape-scale. An integrative approach that combines taxonomic, phylogenetic and functional facets of alpha and beta diversity will provide more efficient and effective biodiversity conservation strategies that maximise the amount of biodiversity protected and ecological resilience.

Our approach will help the understanding of biodiversity-environment relationships that are fundamental for linking theory to management and the development of sound management actions for ponds in the face of environmental change. As global change threatens biodiversity and ultimately ecosystem services humans are relying on (IPBES 2019), we suggest that future studies should incorporate functional and phylogenetic diversity to characterise ecosystem functions and services. Doing so, would also help predict how global change will alter the functioning and evolutionary capability of pond biota in the future.

\section{References}

Arnan, X., Cerdá, X. Retana, J., 2017. Relationships among taxonomic, functional, and phylogenetic ant diversity across the biogeographic regions of Europe. Ecography 40, 448-457.

Baselga, A., 2010. Partitioning the turnover and nestedness components of beta diversity. Glob. Ecol. 
Biogeogr. 19, 134-143.

Baselga, A., Gómez-Rodríguez, C. Lobo, J. M., 2012. Historical legacies in world amphibian diversity revealed by the turnover and nestedness components of beta diversity. PLoS One 7, p.e32341.

Baselga, A., D. Orme, S. Villeger, D. J. Bortoli, F. Leprieur., 2017. betapart: Partitioning beta diversity into turnover and nestedness components. R package version 1.4.1.

Biggs, J. et al., 1998. A guide to the methods of the National Pond Survey. Oxford, UK: Pond Action. Biggs, J., Williams, P., Whitfield, M., Nicolet, P. Weatherby, A., 2005. 15 years of pond assessment in Britain: results and lessons learned from the work of pond conservation. Aquat. Conserv. mar. freshw. Ecosys. 15, 693-714.

Borcard, D. Legendre, P., 2002. All-scale analysis of ecological data by means of principal coordinates of neighbour matrices. Ecol. Model. 153, 51-68.

Borcard, D., Legendre, P. Drapeau, P. 1992. Partialling out the spatial component of ecological variation. Ecology, 73, 1045-1055.

Bush, A., Harwood, T., Hoskins, A.J., Mokany, K. Ferrier, S., 2016. Current uses of beta-diversity in biodiversity conservation: A response to Socolar et al., Trends Ecol. Evol. 31, 337-338.

Cai, J., Zhang, M., Xu, J. Heino, J., 2018. Geographical gradients in the biodiversity of Chinese freshwater molluscs: Implications for conservation. Divers. Distrib. 24, 485-496

Cardoso, P., Rigal, F., Carvalho, J.C., Fortelius, M., Borges, P.A., Podani, J. Schmera, D., 2014. Partitioning taxon, phylogenetic and functional beta diversity into replacement and richness difference components. J. Biogeogr. 41, 749-761.

Cham, S., 2009. Field guide to the larvae and exuviae of British dragonflies Volume 2: Damselflies (Zygoptera). Peterborough, UK: The British Dragonfly Society.

Cisneros, L.M., Fagan, M.E. Willig, M. R., 2015. Effects of human_modified landscapes on taxonomic, functional and phylogenetic dimensions of bat biodiversity. Divers. Distrib. 21, 523-533. Davies. C Edwards. F., 2011. A coded checklist of macroinvertebrates occurring in Fresh Water in the British Isles. Centre for Ecology and Hydrology. Available at:

http://nora.nerc.ac.uk/15232/1/CEHCodeListOctober2011.pdf. [last accessed 06/11/2018].

Demars, B.O., Kemp, J. L., Friberg, N., Usseglio-Polatera, P. Harper, D. M., 2012. Linking biotopes to invertebrates in rivers: biological traits, taxonomic composition and diversity. Ecol. Indic. 23, 301311.

Devictor, V., Mouillot, D., Meynard, C., Jiguet, F., Thuiller, W. Mouquet, N., 2010. Spatial mismatch and congruence between taxonomic, phylogenetic and functional diversity: the need for integrative conservation strategies in a changing world. Ecol. Let. 13, 1030-1040.

Dray, S., Dray, S., Pélissier, R., Couteron, P., Fortin, M.J., Legendre, P., Peres-Neto, P.R., Bellier, E., Bivand, R., Blanchet, F.G., De Cáceres, M., Dufour, A.B., 2012. Community ecology in the age of multivariate multiscale spatial analysis. Ecol. Monogr. 82, 257-275.

Dray, S., Choler, P., Dolédec, S., Peres-Neto, P.R., Thuiller, W., Pavoine, S. ter Braak, C.J., 2014. Combining the fourth_corner and the RLQ methods for assessing trait responses to environmental 
variation. Ecology 95, 14-21.

EC. 1992. Council Directive 92/43/EEC on the conservation of natural habitats and of wild fauna and flora, 22/07/1992. Official Journal L, 206: 7-50.

Edington, J. M. Hildrew, A. G., 1995. A revised key to the caseless caddis larvae of the British Isles Freshwater Biological Association Scientific Publication No. 53, Cumbria, UK: Freshwater Biological Association.

Elliot, J. M. Mann, K. H., 1979. A key to the British freshwater Leeches with notes on their lifecycles and ecology. Freshwater Biological Association Scientific Publication No. 40, Cumbria, UK:

Freshwater Biological Association.

Elliot, J. M., Humpesch, U. H. Macan, T. T., 1988. Larvae if the British Ephemeroptera. Freshwater Biological Association Scientific Publication No. 49, Cumbria, UK: Freshwater Biological Association.

Florencio, M., Díaz-Paniagua, C., Gómez-Rodríguez, C. Serrano, L., 2014. Biodiversity patterns in a macroinvertebrate community of a temporary pond network. Insect Conservation and Diversity, 7, 421.

Foster, G. N. Friday, L. E., 2011. Keys to adults of the water beetles of Britain and Ireland (part 1). Shrewsbury, UK: Field Studies Council.

Fres, C. O. H., 1985. The dragonflies of Great Britain and Ireland. Essex, UK: Harley Books. Friday, L. E., 1988. A key to the adults of British Water Beetles. Field Studies 7, 1-151.

Gianuca, A. T., Declerck, S. A., Lemmens, P. De Meester, L., 2017. Effects of dispersal and environmental heterogeneity on the replacement and nestedness components of diversity. Ecology 98, 525-533.

Gianuca, A. T., Engelen, J., Brans, K. I., Hanashiro, F. T. T., Vanhamel, M., van den Berg, E. M., Souffreau, C. Meester, L. D., 2018. Taxonomic, functional and phylogenetic metacommunity ecology of cladoceran zooplankton along urbanization gradients. Ecography 41, 183-194.

Giraudoux, P., 2017. pgirmess: Data analysis in ecology. R package version 1.6.7.

Gledhill, T., Sutcliffe, D. W. Williams, W. D., 1993. British Freshwater Crustacea Malacostraca A key with ecological notes. Freshwater Biological Association Scientific Publication No. 52, Cumbria, UK: Freshwater Biological Association.

Google Earth, 2017. https://earth.google.com [Last accessed 24/11/2017].

Gower, J. C., 1971. A general coefficient of similarity and some of its properties. Biometrics 27, 857871.

Hassall, C., Hollinshead, J. and Hull, A., 2011. Environmental correlates of plant and invertebrate species richness in ponds. Biodivers. Conserv. 20, 3189- 3222.

Heino, J. Tolonen, K. T., 2017a. Untangling the assembly of littoral macroinvertebrate communities through measures of functional and phylogenetic alpha diversity. Freshwater Biol. 62, 1168-1179. Heino, J. Tolonen, K. T., 2017b. Ecological drivers of multiple facets of beta diversity in a lentic macroinvertebrate metacommunity. Limnol. Oceanogr. 62, 2431-2444.

Heino, J., Bini, L.M., Andersson, J., Bergsten, J., Bjelke, U. Johansson, H., 2017c. Unravelling the 
correlates of species richness and ecological uniqueness in a metacommunity of urban pond insects. Ecol. Indic. 73, 422-431.

Heino, J., Alahuhta, J., Ala-Hulkko, T., Antikainen, H., Bini, L.M., Bonada, N., Datry, T., Er_s, T., Hjort, J., Kotavaara, O., Melo, A.S. Soininen, J., 2017d. Integrating dispersal proxies in ecological and environmental research in the freshwater realm. Environ. Rev. 25, 334 - 349.

Heino, J., Mykrä, H., Kotanen, J., 2008. Weak relationships between landscape characteristics and multiple facets of stream macroinvertebrate biodiversity in a boreal drainage basin. Landsc. Ecol. 23, $417-426$.

Heino, J., Soininen, J., Lappalainen, J., Virtanen, R., 2005. The relationship between species richness and taxonomic distinctness in freshwater organisms. Limnol. Oceanogr. 50, 978 - 986.

Heino, J., 2013. Does dispersal ability affect the relative importance of environmental control and spatial structuring of littoral macroinvertebrate communities? Oecologia 171, 971-980.

Heino, J., Melo, A.S., Siqueira, T., Soininen, J., Valanko, S. Bini, L.M., 2015. Metacommunity organisation, spatial extent and dispersal in aquatic systems: patterns, processes and prospects.

Freshwater Biol. 60, 845-869.

Hill, M. J., Heino, J., Thornhill, I., Ryves, D. B. Wood, P. J., 2017. Effects of dispersal mode on the environmental and spatial correlates of nestedness and species turnover in pond communities. Oikos 126, 1575-1585.

Hill, M. J., Mathers, K. L. Wood, P. J., 2015. The aquatic macroinvertebrate biodiversity of urban ponds in a medium sized European town (Loughborough, UK). Hydrobiologia 760, 225-238.

Hill, M.J., Biggs, J., Thornhill, I., Briers, R.A., Ledger, M., Gledhill, D.G., Wood, P.J. Hassall, C., 2018. Community heterogeneity of aquatic macroinvertebrates in urban ponds at a multi-city scale. Landsc. Ecol. 33, 389-405.

Hynes, H. B. N., 1984. A key to the adults and nymphs of the British Stoneflies (Plecoptera) with notes on their ecology and distribution. Freshwater Biological Association Scientific Publication No. 17, Cumbria, UK: Freshwater Biological Association.

IPBES, 2019. IPBES Summary for policymakers of the global assessment report on biodiversity and ecosystem services of the Intergovernmental Science-Policy Platform on Biodiversity and Ecosystem Services. Available at:

https://www.ipbes.net/sites/default/files/downloads/spm_unedited_advance_for_posting_htn.pdf. [last accessed 10/05/2019].

Kembel, S. W., Ackerly, D. D., Blomberg, S. P., Cornwell, W. K., Cowan, P. D., Helmus, M. R., Morlon, H., and Campbell, O.W., 2016. picante: R tools for integrating phylogenies and ecology. R package version 1.6.2.

Laliberte, E., Legendre, P., and Shipley, B., 2014. FD: Measuring functional diversity from multiple traits, and other tools for functional ecology. R package version 1.0.12.

Legendre, P., and Birks, H J. B., 2012. From classical to canonical conservation. - In: Birks, H. J. B., Legendre, P. and Legendre, L., 2012. Numerical Ecology, 3rd English Edition. Amsterdam: Elsevier. Legendre, P. et al., 2012. PCNM: MEM spatial eigenfunction and principal coordinate analyses. R 
package version 2.1-2.

Legendre, P., 2014. Interpreting the replacement and richness difference components of beta diversity. Glob. Ecol. Biogeogr. 23, 1324-1334.

Macan, T. T., 1977. A Key to the British Fresh- and Brackish- Water Gastropods with Notes on their Ecology. Freshwater Biological Association Scientific Publication No. 13, Cumbria, UK: Freshwater Biological Association.

MacArthur, R. H. Wilson, E.O., 1967. The Theory of Island Biogeography. Princeton, USA:

Princeton University Press.

Merritt, R. W. Cummins, K. W., 1996. An introduction to the aquatic insects of North America (3rd ed.). Dubuque: Kendall/Hunt Publishing.

Meynard, C. N., Devictor, V., Mouillot, D., Thuiller, W., Jiguet, F., Mouquet, N., 2011. Beyond taxonomic diversity patterns: How do $\mathrm{a}, \mathrm{b}$ and c components of bird functional and phylogenetic diversity respond to environmental gradients across France? Glob. Ecol. Biogeogr. 20, 893-903. Myers, J.A., Chase, J.M., Jiménez, I., Jørgensen, P.M., Araujo_Murakami, A., Paniagua_Zambrana, N. Seidel, R., 2013. Beta_diversity in temperate and tropical forests reflects dissimilar mechanisms of community assembly. Ecology letters, 16, 151-157.

Oertli, B., Indermuehle, N., Angélibert, S., Hinden, H. Stoll, A., 2008. Macroinvertebrate assemblages in 25 high alpine ponds of the Swiss National Park (Cirque of Macun) and relation to environmental variables. Hydrobiologia 597, 29-41.

Oertli, B., Joye, D. A., Castella, E., Juge, R., Cambin, D. Lachavanne, J. B., 2002. Does pond size matter? The relationship between pond area and biodiversity. Biol. Conserv. 104, 59-70

Oksanen, J., Blanchet, F.G., Friendly, M., Kindt, R., Legendre, P., McGlinn, D., Minchin, P.R., O’Hara, R.B., Simpson, G.L., Solymos, P., Henry, M., Stevens, H., Szoecs, E., Wagner, H., 2017. Vegan: Community Ecology Package. R package version 2.4-0. [Accessible at http://CRAN.R project.org/package $=$ vegan].

Paradis, E. et al., 2017. ape: Analyses of phylogenetics and evolution. R package 5.0.

Petchey, O.L. Gaston, K.J., 2006. Functional diversity: back to basics and looking forward. Ecol. lett. 9, 741-758.

Peres-Neto, P. R., Legendre, P., Dray, S. and Borcard, D., 2006. Variation partitioning of species data matrices: estimation and comparison of fractions. Ecology 87, 2614-2625.

R Development Core Team., 2016. R: A Language and Environment for Statistical Computing. - R Foundation for Statistical Computing.

Ribeiro, R., Carretero, M.A., Sillero, N., Alarcos, G., Ortiz-Santaliestra, M., Lizana, M. Llorente, G.A., 2011. The pond network: can structural connectivity reflect on (amphibian) biodiversity patterns? Landsc. Ecol. 26, 673-682.

Richardson, D.M. Whittaker, R. J., 2010. Conservation biogeography-foundations, concepts and challenges. Divers. Distrib. 16, 313-320.

Ricklefs, R.E., 2004. A comprehensive framework for global patterns in biodiversity. Ecol. Lett. 7, 115. 
Rocha, M.P., Bini, L.M., Domisch, S., Tolonen, K.T., Jyrkänkallio-Mikkola, J., Soininen, J., Hjort, J. Heino, J., 2018. Local environment and space drive multiple facets of stream macroinvertebrate beta diversity. J. Biogeogr. in press.

Ruhi, A., Boix, D., Gascon, S., Sala, J., Batzer, D., 2013. Functional and phylogenetic relatedness in temporary wetland invertebrates: Current macroecological patterns and implications for future climatic change scenarios. PLoS One 8, e81739.

Rundle, S. D., Foggo, A., Choiseul, V. Bilton, D. T., 2002. Are distribution patterns linked to dispersal mechanisms? An investigation using pond invertebrate assemblages. Freshwater Biol. 47, 1571-1581.

Sayer, C. D., Andrews, K., Shilland, E., Edmonds, N., Edmonds_Brown, R., Patmore, I. R., Emson, D. Axmacher, J., 2012. The role of pond management for biodiversity conservation in an agricultural landscape. Aquat. Conserv. Mar. Freshw. Ecosys. 22, 626-638.

Savage, A. A., 1989. Adults of the British aquatic Hemiptera Heteroptera: a key with ecological notes. Freshwater Biological Association Scientific Publication No. 50, Cumbria, UK: Freshwater Biological Association.

Schmera, D., Podani, J., Heino, J., Er_s, T., Poff, N. L., 2015. A proposed unified terminology of species traits in stream ecology. Freshw. Sci. 34, 823-830.

Siqueira, T., Bini, L.M., Roque, F.O., Marques Couceiro, S.R., Trivinho_Strixino, S., Cottenie, K., 2012. Common and rare species respond to similar niche processes in macroinvertebrate metacommunities. Ecography, 35, 83-192.

Smith, K. G. V., 1989. An introduction to the immature stages of British flies Diptera Larva, with notes on eggs, Puparia and Pupae. London, UK: Royal Entomological Society of London.

Socolar, J. B., Gilroy, J. J., Kunin, W. E. Edwards, D. P., 2016. How should beta-diversity inform biodiversity conservation? Trends Ecol. Evol. 31, 67-80.

Soininen, J., 2016. Spatial structure in ecological communities - a quantitative analysis. Oikos 125, 160 - 166.

Stein, A., Gerstner, K., Kreft, H., 2014. Environmental heterogeneity as a universal driver of species richness across taxa, biomes and spatial scales. Ecol. Lett. 17, 866-880.

Strayer, D.L. Dudgeon, D., 2010. Freshwater biodiversity conservation: recent progress and future challenges. J. North Am. Benthological Soc. 29, 344-358.

Strecker, A. L., Olden, J. D., Whittier, J. B., Paukert, C. P., 2011. Defining conservation priorities for freshwater fishes according to taxonomic, functional, and phylogenetic diversity. Ecol. Appl. 21, 3002-3013.

Tachet, H., Bournaud, M., Richoux, P. Usseglio-Polatera, P. 2010. Invertébrés d'eau douce: systématique, biologie, écologie. Paris, France: CNRS Editions.

Thornhill, I.A., Biggs, J., Hill, M.J., Briers, R., Gledhill, D., Wood, P.J., Gee, J.H., Ledger, M. Hassall, C., 2018. The functional response and resilience in small waterbodies along land_use and environmental gradients. Glob. Chang. Biol. 24, 3079-3092.

Usseglio_Polatera, P., Bournaud, M., Richoux, P., Tachet, H., 2000. Biological and ecological traits of 
benthic freshwater macroinvertebrates: relationships and definition of groups with similar traits. Freshwater Biol. 43, 175-205.

Vanschoenwinkel, B., De Vries, C., Seaman, M., Brendonck, L., 2007. The role of metacommunity processes in shaping invertebrate rock pool communities along a dispersal gradient. Oikos 116, 1255 $-1266$.

Vanschoenwinkel, B., Buschke, F., Brendonck, L., 2013. Disturbance regime alters the impact of dispersal on alpha and beta diversity in a natural metacommunity. Ecology 94, 2547-2557.

Viana, D. S., Figuerola, J., Schwenk, K., Manca, M., Hobaek, A., Mjelde, M., Preston, C. D., Gornall, R. J., Croft, M. J., King, R. A., Green, A. J. Santamaria, L., 2016. Assembly mechanisms determining high species turnover in aquatic communities over regional and continental scales. Ecography 39, 281 -288 .

Villéger, S., Miranda, J.R., Hernandez, D.F. and Mouillot, D., 2012. Low functional_-diversity despite high taxonomic _-diversity among tropical estuarine fish communities. PloS One 7, p.e40679. Wallace, I. D., Wallace, B. Philipson, G. N. 2003. Case-bearing caddis larvae of Britain and Ireland. Freshwater Biological Association Scientific Publication No. 61, Cumbria, UK: Freshwater Biological Association.

Webb, C. O. et al., 2002. Phylogenies and community ecology. Annu. Rev. Ecol. Evol. Syst. 33, 475 -505 .

Wellnitz, T. and Poff, N.L., 2001. Functional redundancy in heterogeneous environments: implications for conservation. Ecol. Lett. 4, 177-179.

Whittaker, R. H., 1960. Vegetation of the Siskiyou Mountains, Oregon and California. Ecol. Monogr. 30, 279-338.

White, J. C., Hill, M. J., Bickerton, M. A., Wood, P. J., 2017. Macroinvertebrate taxonomic and functional trait compositions within lotic habitats affected by river restoration practices. Environ. Manage. 60, 513-525.

Williams, P., Whitfield, M., Biggs, J., Bray, S., Fox, G., Nicolet, P., Sear, D., 2003. Comparative biodiversity of rivers, streams, ditches and ponds in an agricultural landscape in Southern England. Biol. Conserv. 115, 329 - 341. 


\section{Tables}

Table 1. Descriptive statistics of measured environmental variables and biodiversity indices across the 95 ponds selected for study. MPD = mean pairwise distance, $\mathrm{SES}=$ standard effects size.

\begin{tabular}{clllll} 
& Mean & \multicolumn{1}{c}{$\begin{array}{c}\text { Standard } \\
\text { Deviation }\end{array}$} & \multicolumn{1}{c}{$\begin{array}{c}\text { Coefficient of } \\
\text { Variation }\end{array}$} & \multicolumn{2}{c}{ Minimum Maximum } \\
Area $\left(\mathbf{m}^{\mathbf{2})}\right.$ & 552.4 & 1457 & 263.7 & 0.8 & 9309 \\
Depth (cm) & 60.7 & 54.9 & 90.4 & 4 & $>100$ \\
Pond Margin Shaded (\%) & 23.4 & 32.6 & 139.1 & 0 & 100 \\
Emergent Macrophytes (\%) & 23.6 & 27.6 & 116.9 & 0 & 100 \\
Submerged Mactophytes & 23.1 & 23.6 & 102.2 & 0 & 100 \\
(\%) & & & 210.4 & 0 & 96.7 \\
Floating Macrophytes (\%) & 9.2 & 19.3 & 8 & 6.2 & 9.8 \\
pH & 7.8 & 0.6 & 53.4 & 63.7 & 1494 \\
Conductivity & 567.2 & 302.9 & 32.8 & 13.1 & 131.6 \\
Dissolved Oxygen (\%) & 75.3 & 24.7 & 77.4 & 0 & 30 \\
Pond Isolation & 9 & 7 & 178.1 & 0 & 14 \\
Pond Connectivity & 3 & 4.7 & 7.1 & 66.7 & 100 \\
Phylogenetic MPD & 80.8 & 5.8 & 96.4 & -2.3 & 3.9 \\
Phylogenetic MPD SES & 1.3 & 1.2 & 8.6 & 0.24 & 0.35 \\
Functional MPD & 0.27 & 0.02 & 87.2 & -1.81 & 2.85 \\
Functional MPD SES & 1.15 & 0.99 & & &
\end{tabular}

\section{Figure legends}

Figure 1. Scatter plots of species richness and (a) functional alpha diversity and (b) phylogenetic alpha diversity.

Figure 2. The relative contribution of PCNM eigenvectors, hydrological proximity effects, landscape type (urban/non-urban) and local environmental variables to: (a) functional alpha diversity (mean pairwise distance), (b) phylogenetic alpha diversity (mean pairwise distances), and (c) taxonomic alpha diversity. Negative fractions are not presented in the figure. Values represent the adjusted R2 values.

Figure 3. The relative contribution of PCNM eigenvectors, hydrological proximity effects, landscape type (urban/non-urban) and local environmental variables to: (a) total phylogenetic beta diversity, (b) total functional beta diversity, (c) phylogenetic turnover, (d) functional turnover, (e) the nestedness component of phylogenetic beta diversity, and (f) the nestedness component of functional beta diversity. Negative fractions are not presented in the figure. Values represent the adjusted R2 values. 
Figures

Figure 1
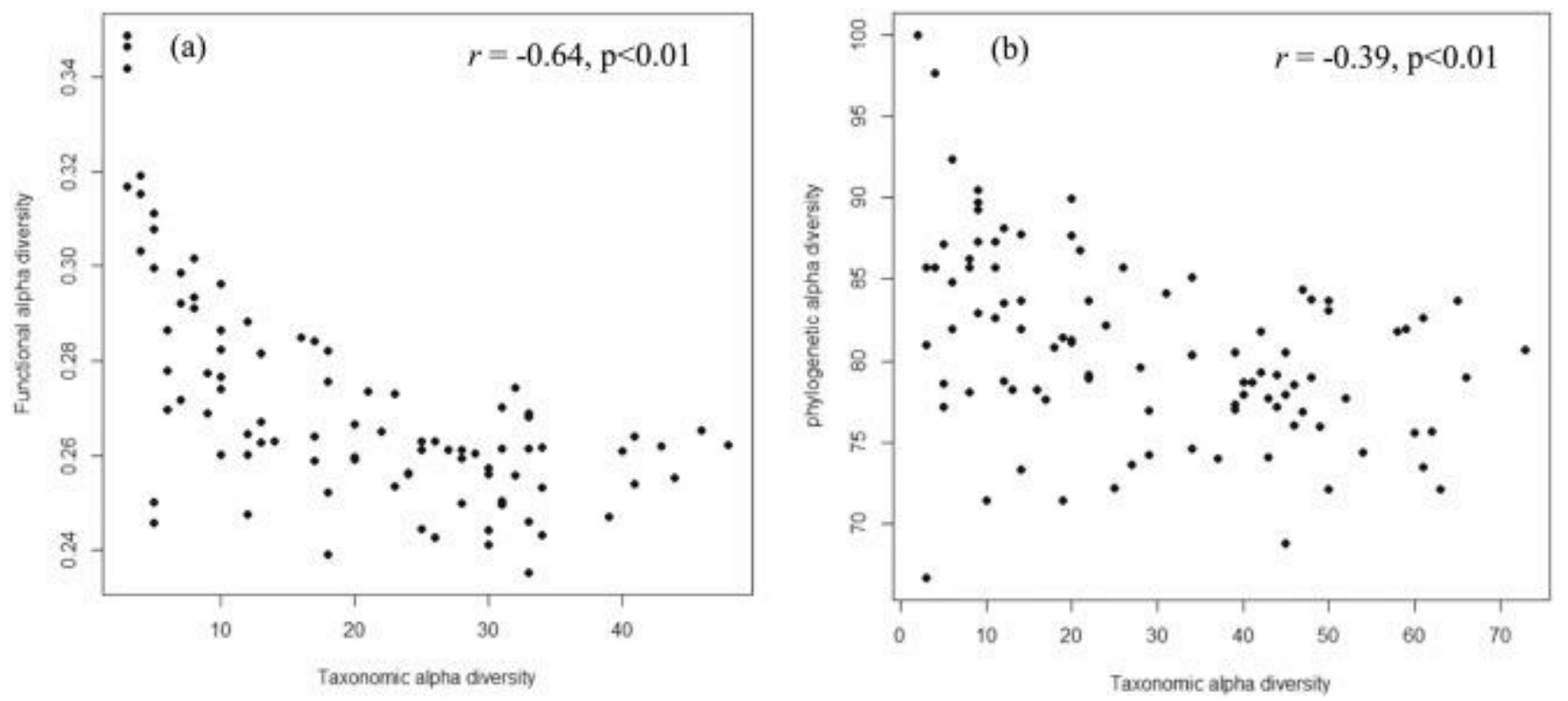

1. Download : Download high-res image (192KB)

2. Download : Download full-size image 
Figure2
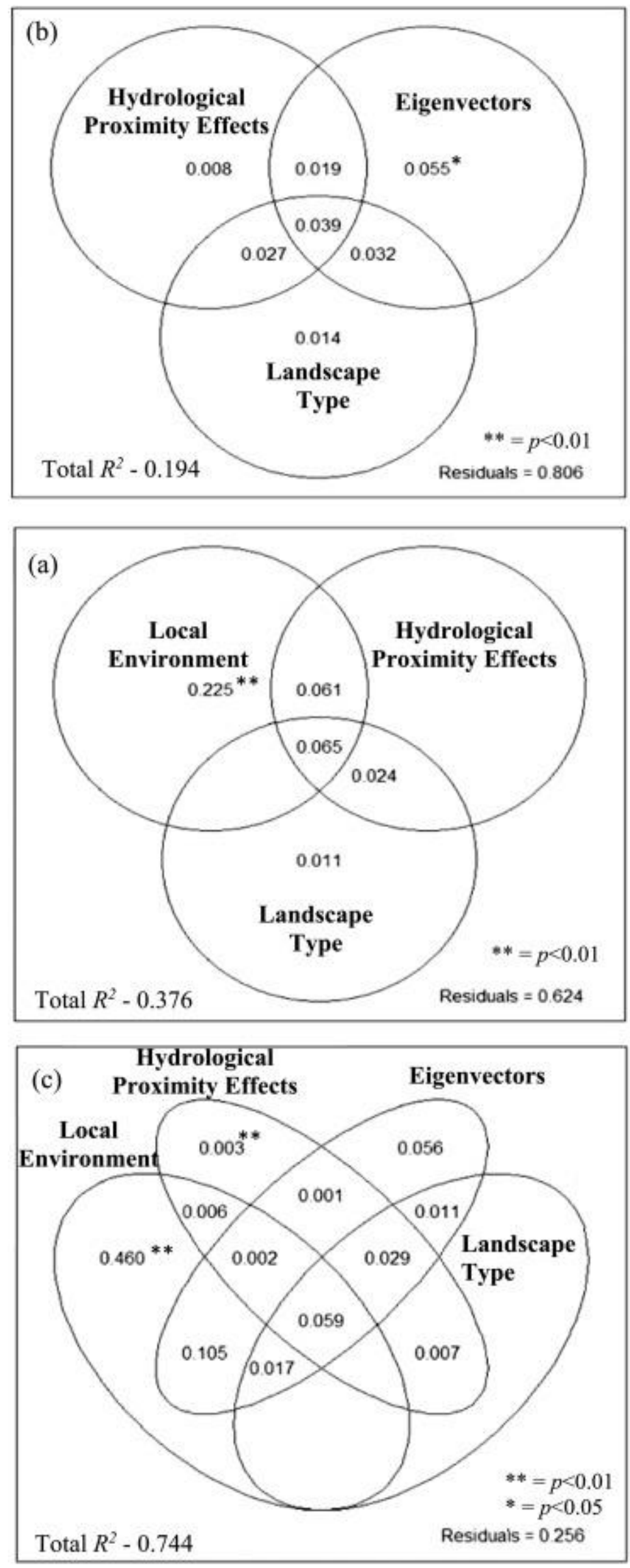

1. Download : Download high-res image (583KB)

2. Download : Download full-size image 
Figure3
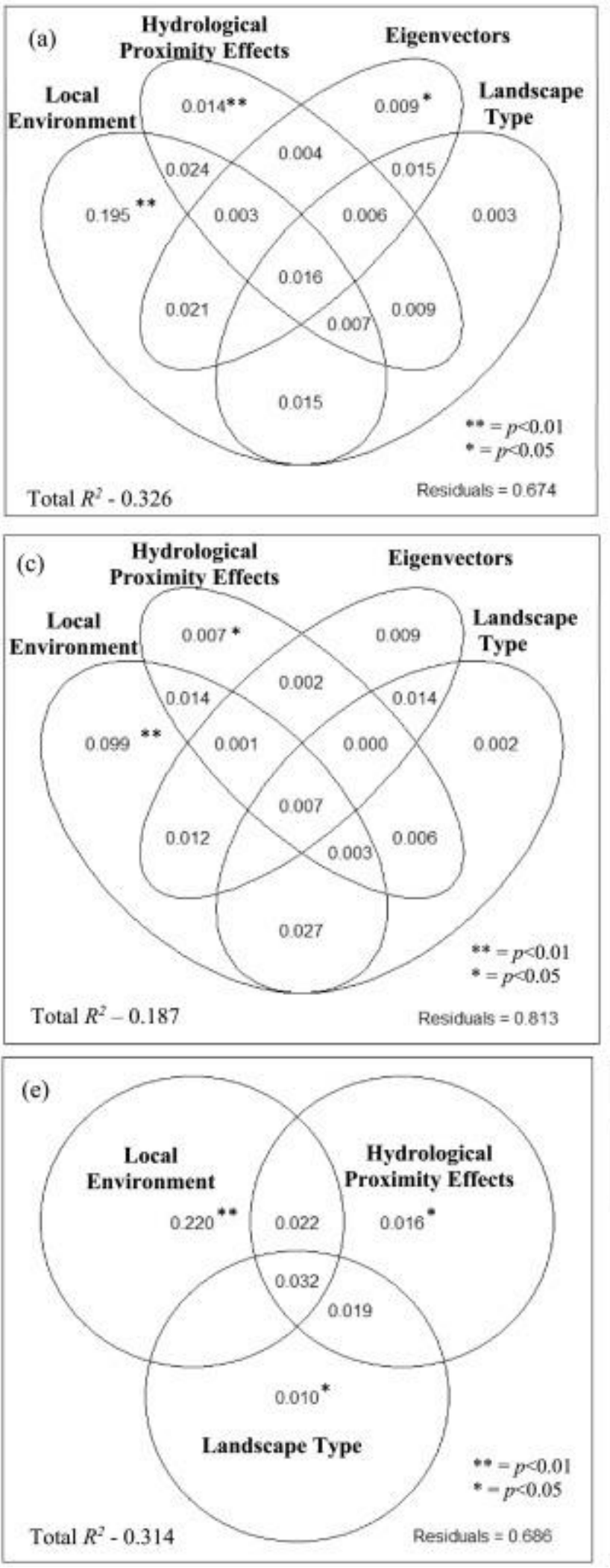
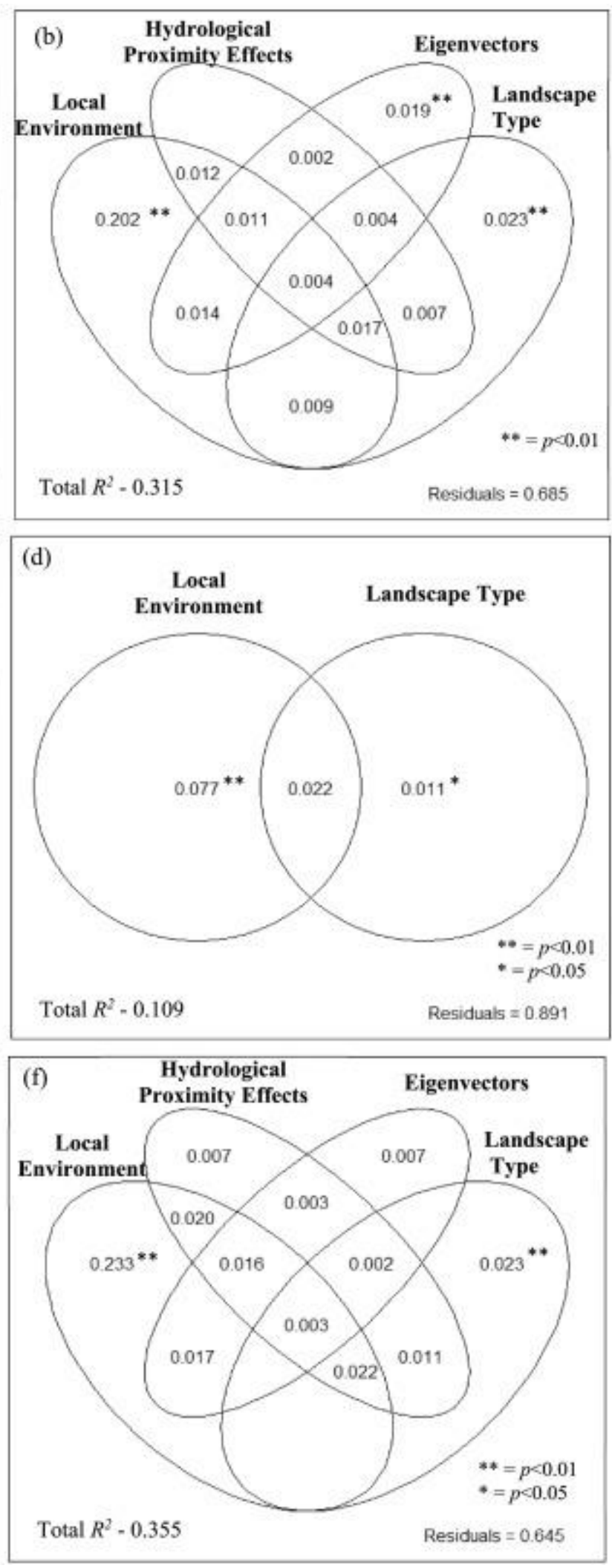

1. Download : Download high-res image (977KB)

2. Download : Download full-size image 